\title{
EXPERIMENTAÇÃO NA CONCEPÇÃO DE PROFESSORES MESTRANDOS EM ENSINO DE CIÊNCIAS NATURAIS
}

\author{
EXPERIMENTATION IN THE CONCEPTION OF TEACHERS ATTENDING \\ MASTER'S DEGREE IN NATURAL SCIENCE TEACHING
}

Douglas Freitas de Oliveira ${ }^{1}$

ORCID iD: 0000-0002-0437-9105

Alzira Silva Moreira ${ }^{2}$

ORCID iD: 0000-0001-8433-1293

Elane Chaveiro Soares ${ }^{3}$

ORCID iD: 0000-0003-0937-9187

Carlos Rinaldi ${ }^{4}$

ORCID iD: 0000-0002-1234-3073

\section{RESUMO}

Com esta pesquisa, objetivou-se compreender as concepções e práticas didático-pedagógicas relacionadas à experimentação desenvolvidas por professores da área de Ciências Naturais (Biologia, Física e Química) que são mestrandos do Programa de Pós-Graduação em Ensino de Ciências Naturais da Universidade Federal de Mato Grosso. Seguiu-se uma abordagem qualitativa, cujo percurso metodológico consistiu em quatro etapas: exploratória (revisão bibliográfica), elaboração dos instrumentos de pesquisa, aplicação de questionários e entrevistas e análises e conclusões. Como resultado, identificou-se três categorias de experimentação (investigativa, demonstrativa e de verificação) presentes nas práticas pedagógicas dos professores participantes, bem como duas abordagens teóricas de aprendizagem (comportamentalista e construtivista). Desta forma, foi possível perceber que houve uma possível ressignificação, sobretudo após ingresso no curso de mestrado profissional, de muitas das concepções sobre atividades experimentais e teorias de aprendizagem que as subjazem, principalmente sobre a ideia do papel do professor e dos estudantes no processo de construção do conhecimento científico.

Palavras-chave: Experimentação. Concepções de professores. Ensino de Ciências.

\footnotetext{
${ }^{1}$ Mestrando em Ensino de Ciências Naturais pela Universidade Federal de Mato Grosso (UFMT). Professor de Química da Educação Básica da Secretaria de Estado de Educação de Mato Grosso (SEDUC/MT), Cuiabá, Mato Grosso, Brasil. Endereço para correspondência: Rua Nortelândia, 169, Parque Amperco, Cuiabá, Mato Grosso, Brasil, CEP: 78042-070. E-mail: freitaseoliveiras@ gmail.com.

${ }^{2}$ Mestranda em Ensino de Ciências Naturais pela Universidade Federal de Mato Grosso (UFMT). Professora de Física da Educação Básica da Secretaria de Estado de Educação de Mato Grosso (SEDUC/MT), Rio Branco, Mato Grosso, Brasil. Endereço para correspondência: Rua Pernambuco, 267, Bairro Vila Maria, Rio Branco, Mato Grosso, Brasil, CEP: 78275-000. E-mail: alzirasm@gmail.com.

${ }^{3}$ Doutora em Educação pela Pontifícia Universidade Católica do Rio Grande do Sul (PUCRS). Professora do Departamento de Química e do Programa de Pós-Graduação em Ensino de Ciências Naturais da Universidade Federal de Mato Grosso (PPGECN/UFMT), Cuiabá, Mato Grosso, Brasil. Endereço para correspondência: Rua dos Papagaios, 119, Quadra 17, Lote 20, Cond. Belvedere, Cuiabá, Mato Grosso, Brasil, CEP: 78075-864. E-mail: elaneufmt@gmail.com.

${ }^{4}$ Doutor em Educação pela Universidade Federal de Mato Grosso (UFMT). Professor Titular do Instituto de Física e do Programa de Pós-Graduação em Ensino de Ciências Naturais da Universidade Federal de Mato Grosso (PPGECN/UFMT), Cuiabá, Mato Grosso, Brasil. Endereço para correspondência: Av. Fernando Correa da Costa, 2.637, Bairro Boa Esperança, Cuiabá, Mato Grosso, Brasil, CEP: 78060-900. E-mail: rinaldi.ufmt@ gmail.com.
} 


\begin{abstract}
This research aimed to know the concepts and didactic-pedagogical practices related to experimentation developed by professors in the area of Natural Sciences (Biology, Physics and Chemistry) who are masters of the Postgraduate Program in Teaching of Natural Sciences of the University as. A qualitative approach was followed whose methodological design consisted of four stages: exploratory (bibliographic review), elaboration of the research tools, application of the questionnaire and interview, analyzes and conclusions. Three categories of experimentation (investigative, demonstrative and verification) can be identified in the pedagogical practices of the participating teachers, as well as two different theoretical approaches to learning (behavioral and constructivist). Finally, it was possible to perceive that there was a possible re-signification, especially after entering the professional master's degree course, many of the conceptions about experimental activities and learning theories that underlie them, mainly on the idea of the role of the teacher and students in the process of construction of scientific knowledge.
\end{abstract}

Keywords/Palabras clave: Experimentation. Teachers conceptions. Science Teaching.

\title{
1 INTRODUÇÃO
}

A área de Ensino de Ciências Naturais tem se preocupado, nos últimos anos, com importantes discussões acerca de concepções e ações que sejam efetivas do ponto de vista dos processos de ensino e aprendizagem. Neste sentido, aponta-se intensas críticas ao atual modelo de ensino, que tem sido caracterizado, na maioria das vezes, como superficial, desconexo da realidade, gerador de obstáculos epistemológicos e pedagógicos (LOPES, 1992; 2007) e de visões deformadas do trabalho científico (GIL-PÉREZ et al., 2001; CACHAPUZ, 2005), bem como por ser profundamente defasado no que se refere à promoção de atividades experimentais (BASSOLI, 2014).

Neste contexto, Moreira e Atx (1991, p. 79) corroboram ao afirmar que há uma crítica constante ao ensino de Ciências Naturais pela ausência da experimentação, ou ainda, por ela ser epistemologicamente frágil (HODSON, 1988). Assim, quando ela acontece, em sala de aula, nota-se comumente que não há uma distinção dos princípios que a norteiam e nem fica claro qual a sua relevância para o processo de ensino-aprendizagem.

Oliveira (2010), por sua vez, argumenta que a experimentação no ensino de Ciências Naturais, quando tem suas potencialidades e limitações reconhecidas, pode favorecer a aprendizagem de saberes conceituais, procedimentais e atitudinais, o que contribui para a efetividade do desenvolvimento escolar. E nesta mesma perspectiva, Moreira e Atx (1991) apontam para a importância da experimentação, pois ela pode "contribuir para aproximar o ensino de Ciências Naturais das características do trabalho científico. A experimentação 
também pode contribuir para a aquisição de conhecimento e para o desenvolvimento mental dos alunos" (p. 79-80).

Quanto às teorias de aprendizagem que fundamentam a prática experimental, é importante destacar que elas são variadas, permitindo promover a experimentação no ambiente escolar desde uma perspectiva mais tradicionalista (ou mecanicista) até aquelas mais construtivistas e humanistas (MOREIRA, 2011).

Moreira e Atx (1991), por exemplo, baseiam-se no entendimento ausubeliano da aprendizagem por descoberta via experimentação. Para tanto, o autor afirma que a experimentação só é efetivada se a situação de aprendizagem for muito bem estruturada e competentemente programada. Ou seja, a noção do trabalho com experimentação como intermédio de ativação à ação mental é mais do que a simples utilização de materiais concretos - que por si só não garantem o sucesso da aprendizagem -, de maneira que compreende a reflexão que surge das situações nas quais esses materiais são empregados e, consequentemente, a maneira como o professor unifica a experimentação em sua argumentação.

Deste modo, considerando tais princípios e a recorrência do tema, objetivou-se compreender, a partir desta pesquisa, as concepções e as práticas didático-pedagógicas relacionadas à experimentação desenvolvidas por professores da área de Ciências Naturais (Biologia, Física e Química) que são mestrandos do Programa de Pós-Graduação em Ensino de Ciências Naturais (Mestrado Profissional) da Universidade Federal de Mato Grosso, ingressantes no ano letivo de 2018.

\section{REFERENCIAIS TEÓRICOS}

Criticado ao longo dos últimos anos - tanto por pesquisadores, quanto por professores -, o ensino de Ciências Naturais tem se apresentado como uma ação distanciada da realidade (LOPES, 1992; 2007; VALENTIM, 2017). Todavia, como contraponto, têm surgido correntes teóricas que propõem um redimensionamento das práticas escolares, visando o desenvolvimento de propostas que possam nortear a superação do modelo tradicional por uma concepção mais inovadora acerca dos processos de ensino-aprendizagem, como aquelas que envolvem a construção de conhecimentos científicos em sala de aula.

Neste sentido, uma metodologia que tem potencial para superar essa lacuna é a experimentação. Segundo Moreira e Atx (1991), a experimentação pode funcionar como um intermediário para ativar a ação mental e que, além de requerer o uso de materiais concretos tanto laboratoriais, quanto alternativos -, permite a reflexão sobre aquilo que sustenta a prática. 
É interessante ressaltar que, de um ponto de vista histórico, a experimentação teve um papel importantíssimo na implementação e consolidação das Ciências Naturais a partir do século XVII, na medida em que as leis formuladas necessitavam passar pelo crivo das situações empíricas propostas, dentro de uma lógica sequencial de elaboração de hipóteses e investigação de consistência (GIORDAN, 1999). Todavia, os tempos atuais são caracterizados por um ensino pouco marcado pela experimentação, o que tem demandado das pesquisas da área de Ensino de Ciências Naturais um denso debate sobre as diversas contribuições, abordagens/categorias e finalidades de se realizar atividades experimentais no ambiente escolar (OLIVEIRA, 2010).

Quanto às finalidades de se desenvolver atividades experimentais para a efetivação dos processos ensino-aprendizagem, Silva et al. (2011) alertam que a ideia da experimentação como simples estratégia de motivação ou de concretização da teoria é reducionista e equivocada, uma vez que estas atividades se constituem numa estrutura e dinâmica próprias, pois podem contribuir para "o desenvolvimento do pensamento analítico, teoricamente orientado" (p. 240), ou seja, a experimentação quando bem planejada, "enseja a possibilidade de fragmentação do objeto concreto em partes, o reconhecimento destas e sua recombinação de um modo novo" (p. 240).

Quanto à categorização das diferentes abordagens de experimentação desenvolvidas no ambiente escolar, Araújo e Abib (2003) e Oliveira (2010) estabelecem três categorias: demonstração/observação, verificação e investigação - descritas a seguir, considerando os pressupostos defendidos por esses autores.

A experimentação por demonstração/observação busca ilustrar alguns aspectos dos fenômenos observados e são concebidas por dois pressupostos diferentes, a demonstração fechada e a demonstração/observação aberta. A primeira é centralizada no professor, que a realiza, e se caracteriza pela ilustração de um determinado fenômeno, enquanto a segunda permite uma maior participação dos alunos no levantamento de hipóteses (ARAÚJO; ABIB, 2003). Ou seja, essas atividades privilegiam a ação do professor (que executa o experimento e fornece as explicações) e coloca os alunos numa posição mais passiva (de observadores) no processo de ensino-aprendizagem. Este tipo de experimentação é marcado ainda por integrar aulas expositivas, com roteiros mais estruturalmente fechados (OLIVEIRA, 2010).

Já na experimentação por verificação, procura-se verificar ou comprovar certos fenômenos que são facilmente previsíveis nas leis e teorias já estabelecidas, cujo objetivo é facilitar a interpretação dos resultados, pois a explicação teórica já é conhecida pelos alunos (OLIVEIRA, 2010). Logo, esta abordagem é baseada na formulação de pressupostos que facilitem a interpretação dos parâmetros que determinam os fenômenos, visando potencializar 
a aprendizagem pela maior participação dos alunos, inclusive estimulando a capacidade de construir generalizações (ARAÚJO; ABIB, 2003).

Por último, a experimentação por investigação se caracteriza por não se fazer uso de roteiros estruturalmente fechados, uma vez que ela é centralizada nos aspectos cognitivos do processo de ensino-aprendizagem, de maneira que visa a promoção da capacidade de julgamento, de generalização e de senso crítico. Nesta abordagem, os professores apenas direcionam as atividades e os alunos é que as executam (OLIVEIRA, 2010). Para tanto, os alunos devem, coletivamente, discutir ideias, levantar hipóteses e utilizar a experimentação como meio para compreender os fenômenos (ARAÚJO; ABIB, 2003).

Quanto aos pressupostos teóricos de aprendizagem que norteiam a experimentação, pode-se tomar como base os escritos de Moreira (2011), em especial duas posições profundamente distintas: a comportamentalista e a construtivista.

Sob a ótica comportamentalista, Moreira (2011) argumenta que a aprendizagem se dá através de comportamentos (observáveis e mensuráveis) que são respostas à estímulos exteriores. Logo, a aprendizagem do aluno se daria por uma mudança de comportamento resultante de estímulos promovidos pelo professor, de forma condicionada e repetitiva - não considerando, portanto, aspectos cognitivos para a construção do conhecimento. Ou seja, a experimentação mais próxima a esta visão teria o aluno como mero observador, enquanto o professor seria o centro do processo de ensino-aprendizagem, cujos experimentos seriam estímulos para a mudança de comportamento - que, neste caso, seria a aprendizagem.

Por outro lado, na concepção construtivista, duas teorias de aprendizagem podem ser destacadas: a sócio-interacionista de Lev Vygotsky e a da aprendizagem significativa de David Ausubel.

A teoria construtivista de Vygotsky tem como foco os instrumentos, signos e sistemas de signos como construções sócio-históricas e culturais, bem como a internalização, no indivíduo, desses instrumentos e signos como uma reconstrução interna em sua mente (MOREIRA, 2011). Ou seja, partindo desse princípio, a experimentação pode ser utilizada como ferramenta de (re)construção do conhecimento, na qual o professor deve assumir a postura de mediador, enquanto o aluno deve devolver ao professor o significado que captou/construiu. Portanto, nesta perspectiva é indispensável o intercâmbio entre professor e aprendiz, sendo a experimentação um propício momento para tal.

Já a teoria da aprendizagem significativa de Ausubel, segundo Moreira (2011), destaca a aprendizagem a partir daquilo que já conhecemos, ou seja, a aprendizagem significativa se dá pela interação entre o novo conhecimento e o conhecimento prévio, de modo que o 
conhecimento novo passa a adquirir significado para o aprendiz quando este tem conhecimentos anteriores que lhe dão base, tornando os novos conhecimentos em conhecimentos prévios mais elaborados em termos de significado e com maior estabilidade. Logo, a experimentação pode ser um recurso metodológico para promover essa transição, possibilitando uma aprendizagem significativa pela construção de conhecimentos no ambiente escolar.

Por fim, Oliveira (2010) corrobora ao argumentar que a experimentação no ensino de Ciências Naturais, dentro dos seus limites e possibilidades, com orientação e planejamento coerentes, pode favorecer: a motivação para aprender; o desenvolvimento da capacidade de trabalho em grupo, da iniciativa pessoal e da tomada de decisão; o estímulo da criatividade; o aprimoramento da capacidade de observação, registro, análise de informações e proposição de hipóteses; a aprendizagem de conceitos científicos e detectar dificuldades conceituais; a discussão da natureza da ciência e do papel do cientista numa investigação; o aprimoramento de habilidades manipulativas; e a compreensão das relações entre Ciência, Tecnologia e Sociedade.

\section{MATERIAIS E MÉTODOS}

A opção metodológica que orientou esta pesquisa foi a de abordagem predominantemente qualitativa, uma vez que a natureza dos dados e sua análise se constituiu numa abordagem mais textual, conforme explicitado por Gonsalves (2007, p. 69) ao afirmar que a pesquisa qualitativa se preocupa mais "[...] com a compreensão, com a interpretação do fenômeno, considerando o significado que os outros dão às suas práticas”. Ou seja, uma investigação qualitativa é aquela que busca, essencialmente, a compreensão de concepções, atitudes e comportamentos a partir da perspectiva dos participantes da investigação (BOGDAN; BIKLEN, 1994).

Assim, considerando os pressupostos de um estudo qualitativo, o percurso metodológico adotado neste trabalho consistiu em uma divisão em quatro etapas simultâneas e interdependentes: a exploratória, a elaboração e a aplicação dos instrumentos de pesquisa, e a análises e conclusões.

A fase exploratória ocorreu basicamente com a revisão de literatura em livros e artigos científicos acerca dos tipos de experimentação adotadas/praticadas no ensino-aprendizagem das Ciências Naturais - em especial, de Biologia, Física e Química -, bem como das suas diferentes relações com algumas categorias teóricas de aprendizagem, considerando especialmente as perspectivas construtivista e comportamentalista. Portanto, é importante destacar que as 
diferentes abordagens sobre o uso da experimentação para o desenvolvimento da aprendizagem foram organizadas em três categorias: a demonstrativa, a investigativa e a de verificação - de acordo com o estudo de Oliveira (2010), que as caracteriza e as descrevem segundo características como o papel dos alunos e do professor no desenvolvimento de atividades experimentais. Por sua vez, as diferentes perspectivas teóricas de aprendizagem foram baseadas no estudo de Moreira (2011), que aborda os principais teóricos e suas contribuições sobre a temática.

Já a elaboração dos instrumentos de pesquisa ocorreu em dois momentos: o primeiro, com a elaboração de um questionário autoaplicável online; e o segundo, com a construção de um roteiro de entrevista semiestruturada. Sendo que a preferência por entrevistas, deve-se à compreensão de que esses instrumentos, conforme contribui Leite (2008, p. 104-105), permitem recolher, por meio de um diálogo orientando, uma determinada informação e/ou concepções do entrevistado. Já a opção por questionários, deve-se à sua particularidade de permitir obter características e informações tanto coletivas quanto individuais (LEITE, 2008, p. 109).

Quanto ao questionário, este foi elaborado com o auxílio da plataforma Google Formulários, e seu posterior envio aos endereços eletrônicos dos sujeitos da pesquisa. Para tanto, o questionário foi estruturado com 34 questões (das quais, 15 eram discursivas) objetivando obter informações sobre: o perfil, a formação acadêmica, a atuação profissional, o último (ou atual) local de trabalho e as concepções e práticas didático-pedagógicas dos participantes relacionadas à experimentação.

O roteiro de entrevista semiestruturada, por sua vez, constituiu-se na tentativa de aprofundar as respostas dadas pelos sujeitos. E por este motivo, foi construído somente após a aplicação e a análise preliminar dos questionários. Além disso, é importante ressaltar que o foco da entrevista foi compreender como os participantes têm desenvolvido práticas experimentais em sala de aula e quais as abordagens que mais utilizam, assim como quais as fundamentações teóricas de aprendizagem que às subjazem.

Quanto à terceira etapa, esta aconteceu com a aplicação do questionário e a realização da entrevista semiestruturada aos sujeitos da pesquisa, que foram os mestrandos do Programa de Pós-Graduação em Ensino de Ciências Naturais da Universidade Federal de Mato Grosso, ingressantes no período letivo de 2018/1 (os quais aceitaram participar da pesquisa registrando o consentimento livre e esclarecido). A realização da entrevista semiestruturada aconteceu via áudio-comunicação (com gravação efetivada a partir do aplicativo Call Record $^{\circledR}$ ) com um grupo menor de pesquisados (três professoras). 
Neste contexto, é necessário ressaltar que a escolha dos sujeitos desta pesquisa se deu por quatro motivos principais: i) por atuarem e/ou já terem atuado na Educação Básica; ii) por ser um grupo formado por professores licenciados nas áreas de Química, Física ou Biologia (que compõem, portanto, a área das Ciências Naturais); iii) por residirem e trabalharem em diferentes instituições de ensino, de diversas cidades do Estado de Mato Grosso; iv) e por serem profissionais em provável situação de ressignificação de suas práticas pedagógicas (uma vez que são mestrandos), inclusive as experimentais. Já a seleção dos sujeitos para participarem da entrevista semiestruturada aconteceu por três principais fatores: pela disponibilidade para a realização desta etapa da pesquisa; por atuarem em três diferentes componentes curriculares das Ciências Naturais; e pelas respostas dadas ao questionário, uma vez que foram as mais representativas e díspares quanto às categorias de experimentação e às concepções de ensinoaprendizagem que as fundamentam.

Por último, a etapa de análises e conclusões aconteceu com o tratamento predominante qualitativo dos dados obtidos nos questionários e nas entrevistas, relacionando-se as respostas dos sujeitos com as categorias de experimentação.

\section{RESULTADOS E DISCUSSÃO}

\subsection{Análise dos questionários}

Entre os dias 29 de junho e 03 de julho de 2018, foi realizada a aplicação do questionário online à oito professores atuantes nos componentes curriculares de Biologia, Física e/ou Química, com idade entre 25 e 42 anos, que são ingressantes do período de 2018/1 do programa de mestrado já citado. Além disso, tais professores residem e trabalham em quatro cidades do Estado de Mato Grosso: Cuiabá, Comodoro, Sorriso e Campo Verde - o que suscita diferentes contextos e realidades educacionais.

Inicialmente, buscando-se estabelecer um panorama da formação acadêmica dos participantes da pesquisa, fez-se um levantamento quanto às áreas de formação e os locais onde realizaram seus respectivos cursos de graduação (Tabela 1). 
DOI: $10.265571 /$ reamec.v8i1.9251

\begin{tabular}{c|c|c|c}
\hline PROFESSORES & FORMAÇÃO & $\begin{array}{c}\text { INSTITUIÇÃO } \\
\text { FORMADORA }\end{array}$ & CURSO DE ESPECIALIZAÇÃO \\
\hline P1 & Química & UFMT (Cuiabá-MT) & $\begin{array}{c}\text { Ciências da Natureza para o Ensino } \\
\text { Fundamental }\end{array}$ \\
\hline P2 & Química & $\begin{array}{c}\text { UNESP (Presidente } \\
\text { Prudente-SP) }\end{array}$ & $\begin{array}{c}\text { Educação à Distância (EAD) } \\
\text { P3 }\end{array}$ \\
\hline Puímica & UFMT (Cuiabá-MT) & $\begin{array}{c}\text { Relações Étnico-Raciais no } \\
\text { Contexto da Educação de Jovens e } \\
\text { Adultos (EJA) }\end{array}$ \\
\hline P5 & Física & UFMT (Cuiabá-MT) & Não possui \\
\hline P6 & Ciências & UNIC (Cuiabá-MT) & $\begin{array}{c}\text { Gestão Ambiental } \\
\text { Biológicas }\end{array}$ \\
\hline P7 & Física & UNICS (Palmas-PR) & Educação à Distância (EAD) \\
\hline P8 & Química & UFMT (Cuiabá-MT) & Não possui \\
\hline & Ciências & UNEMAT (Cáceres-MT) & $\begin{array}{c}\text { Ciências Ambientais com foco em } \\
\text { Ensino de Botânica e Fauna }\end{array}$ \\
\hline
\end{tabular}

Tabela 1 - Formação acadêmica dos participantes da pesquisa.

Fonte: Elaboração dos autores (2019).

Na tentativa de saber como se deu a formação de nível superior em termos de estratégias e princípios didático-pedagógicos foi questionado a respeito dos recursos pedagógicos que eles haviam tido contato, como: livros didáticos, livros paradidáticos (ou diversos, que não o didático), jogos e/ou atividades lúdicas, atividades experimentais, aula de campo e/ou visita à espaços fora do ambiente escolar, filmes e/ou vídeos, celular e/ou computador com acesso à internet, atividades esportivas, artísticas e/ou culturais. Sendo que a experimentação foi a única resposta unânime entre os entrevistados - fato que pode ser explicado pela própria natureza experimental das Ciências Naturais.

Neste contexto, destaca-se novamente a diversidade de atuação desses profissionais (Tabela 2), em diferentes sistemas e níveis de ensino, assim como, com diferentes períodos de experiências docentes, o que pode possibilitar uma variedade de concepções sobre o fazer educacional.

\begin{tabular}{c|c|c|c}
\hline PROFESSORES & $\begin{array}{c}\text { TEMPO DE } \\
\text { ATUAÇÃO }\end{array}$ & SISTEMAS DE ENSINO & $\begin{array}{c}\text { NÍVEIS DE ENSINO } \\
\text { EM QUE ATUA }\end{array}$ \\
\hline P1 & 18 anos & Pública estadual, privada & Ensino médio \\
\hline P2 & 10 anos & Pública estadual & Ensino fundamental e médio \\
\hline P3 & 19 anos & Pública estadual & Ensino médio \\
\hline P4 & 10 anos & Pública estadual & Ensino médio \\
\hline P5 & 10 anos & Pública estadual, privada & $\begin{array}{c}\text { Ensino fundamental e } \\
\text { médio, cursos técnicos ou } \\
\text { profissionalizantes, cursos } \\
\text { pré-vestibulares }\end{array}$ \\
\hline P6 & 14 anos & Pública estadual, privada & Ensino fundamental e médio \\
\hline P7 & 5 meses & Pública estadual & Ensino médio \\
\hline P8 & 10 anos & Pública estadual & Ensino fundamental e médio \\
\hline
\end{tabular}


Por outra perspectiva, buscando-se saber sobre o atual (ou último) local de trabalho desses profissionais, foram realizadas perguntas quanto a (in) adequação do ambiente escolar para desenvolver as atividades pedagógicas, considerando-se assim os aspectos de estrutura física, de organização administrativo-pedagógica e de relação profissional entre os trabalhadores da escola. Em resposta, todos indicaram que consideravam adequado (ou com mais aspectos positivos do que negativos) o seu ambiente de trabalho, cujas principais justificativas dadas foram: a boa relação com os demais professores e a coordenação/gestão pedagógica (presente em quatro respostas), a estrutura física adequada (constante em duas afirmações) e ambiente favorável para a aprendizagem (presente em uma resposta), bem como uma crítica à falta de materiais "especializados" que, segundo a entrevistada P6, contribui para “uma aprendizagem precária”. Neste contexto, é importante destacar que a falta de insumos para experimentos e laboratórios não foram consideradas explicitamente como uma dificuldade para desenvolver a prática pedagógica cotidiana na escola.

Quanto à prática didático-pedagógica dos entrevistados, objetivou-se compreender quais das estratégias e princípios para o ensino-aprendizagem (citados anteriormente) eles utilizavam em sala de aula. Para tanto, sete dos sujeitos afirmaram fazer uso da experimentação, com a frequência de pelo menos uma vez por: semana (segundo duas indicações), mês (duas respostas) e bimestre (duas citações). Já em relação aos dois participantes que afirmaram não realizar atividades experimentais: um (P7) argumentou que realizaria apenas no bimestre seguinte, enquanto outro (P6) afirmou que não as realiza principalmente por não haver laboratório de Ciências ou outro espaço físico adequado, além de não ter disponibilidade de tempo para realizar a preparação dos experimentos.

Perguntados também sobre quais os motivos para desenvolverem experimentos em sala de aula (Tabela 3), os professores responderam as seguintes afirmativas:

\begin{tabular}{l|l}
\hline \multicolumn{1}{c|}{ MOTIVOS DA UTILIZAÇÃO DE PRÁTICAS EXPERIMENTAIS } & \multicolumn{1}{c}{ PROFESSORES } \\
\hline Ilustrar um conteúdo específico & P1, P5, P6, P8 \\
\hline Demonstrar uma teoria já estudada em sala & P1, P5, P6 \\
\hline Verificar se a prática condiz com a teoria & $\mathrm{P} 4$ \\
\hline Problematizar algum conteúdo específico considerando aspectos sociais & $\mathrm{P} 1, \mathrm{P} 6$ \\
\hline Motivar os alunos com uma maneira divertida de aprender & $\mathrm{P} 1, \mathrm{P} 4, \mathrm{P} 5, \mathrm{P} 6, \mathrm{P} 8$ \\
\hline Investigar os diferentes resultados que se pode obter a partir de um experimento & $\mathrm{P} 1, \mathrm{P} 3, \mathrm{P} 6, \mathrm{P} 8$ \\
\hline Compreender como se dá o conhecimento científico & $\mathrm{P} 1, \mathrm{P} 2, \mathrm{P} 3, \mathrm{P} 5$ \\
\hline Promover a construção conceitual & $\mathrm{P} 1, \mathrm{P} 3, \mathrm{P} 4, \mathrm{P} 6$ \\
\hline Mostrar como os cientistas descobriram um determinado fenômeno natural & $\mathrm{P} 3$ \\
\hline Não declarado & $\mathrm{P} 7$ \\
\hline
\end{tabular}

Tabela 3 - Motivos do uso de atividades experimentais pelos professores.

Fonte: Elaboração dos autores (2019). 
Neste sentido, ressalta-se que as três categorias de experimentação (demonstrativa, investigativa e de verificação) descritas por Oliveira (2010) e Araújo e Abib (2003) foram citadas.

As concepções que consideram (ou que utilizam) as atividades experimentais como formas de ilustrar o conteúdo e demonstrar uma teoria tem caráter demonstrativo, sendo esta a prática mais recorrente (juntas foram citadas sete vezes) na ação docente dos entrevistados. Já as atividades experimentais com a intenção de investigar diferentes resultados obtidos com experimentos e de problematizar conteúdos têm cunho experimental mais investigativo, sendo citada seis vezes pelos sujeitos. Por último, a experimentação com o objetivo de verificar a teoria na prática tem uma vertente de experimentação de verificação, sendo a ação experimental menos apontada pelos professores (com apenas uma citação).

É importante destacar que a ideia que envolve a experimentação como uma perspectiva de compreender como se dá o conhecimento científico (quatro citações) é uma questão sobretudo epistemológica, uma vez que se permite dialogar com questões que visam evitar a promoção de visões deformadas do trabalho científico e de possíveis obstáculos epistemológicos (e, consequentemente, pedagógicos) na construção de conhecimentos científicos em sala de aula.

Além disso, a ideia da experimentação como ação lúdica que motive os alunos para aprender (citada por cinco dos entrevistados), envolve duas problematizações: a função da ludicidade no ensino-aprendizagem deve ser orientada com a ação didática, de modo que seja, ao mesmo tempo e de forma equilibrada, lúdica e educativa (SOARES, 2004; OLIVEIRA; SOARES, 2010); e a ideia de motivação, que deve ser encarada como subjetiva ao indivíduo, não sendo instalada puramente por ações exteriores (CERQUEIRA et al., 2004). E a última das citações, a experimentação para promover a construção conceitual (indicada por quatro professores), relaciona-se diretamente com a concepção construtivista, em conformidade com os apontamentos de Moreira (2011).

Quanto aos momentos em que os sujeitos inserem aulas experimentais em seus planejamentos didático-pedagógicos, estes podem ser observados no Tabela 4. 


\begin{tabular}{l|l}
\hline \multicolumn{1}{c|}{ MOMENTOS DA UTILIZAÇÃO DE PRÁTICAS EXPERIMENTAIS } & \multicolumn{1}{|l}{ PROFESSORES } \\
\hline Não utilizo práticas experimentais em minhas aulas & - \\
\hline Para introduzir um novo conceito & $\mathrm{P} 1, \mathrm{P} 6, \mathrm{P} 8$ \\
\hline Para confirmar o que já havia sido estudado anteriormente & $\mathrm{P} 4, \mathrm{P} 5, \mathrm{P} 6, \mathrm{P} 8$ \\
\hline Para revisar conceitos já estudados & $\mathrm{P} 4, \mathrm{P} 5, \mathrm{P} 8$ \\
\hline Para complementar um conteúdo já estudado & $\mathrm{P} 1, \mathrm{P} 2, \mathrm{P} 3, \mathrm{P} 4, \mathrm{P} 5, \mathrm{P} 8$ \\
\hline Para avaliar a construção de conceitos & $\mathrm{P} 3, \mathrm{P} 5, \mathrm{P} 8$ \\
\hline Para verificar se houve a transmissão correta de conceitos & $\mathrm{P} 8$ \\
\hline Como atividade de recuperação para os alunos que não atingiram a média escolar & - \\
\hline Não respondeu & $\mathrm{P} 7$ \\
\hline
\end{tabular}

Tabela 4 - Uso de atividades experimentais no planejamento dos professores. Fonte: Elaboração dos autores (2019).

A partir destas respostas, destaca-se que distintas perspectivas teóricas de aprendizagem e de categorias de experimentação foram contempladas. A ideia de confirmar o que já havia sido estudado anteriormente (quatro indicações) está fortemente ligada à concepção de experimentação de verificação, uma vez que se busca verificar na prática o que aponta a teoria. Além disso, o uso de atividades experimentais para verificar se houve a "transmissão correta" de conceitos (uma indicação) pressupõe uma abordagem comportamentalista da aprendizagem, em que o professor se constitui como o centro do processo de ensino-aprendizagem e detentor do conhecimento, devendo, portanto, transmitir esse conhecimento e estimular a mudança de comportamento dos alunos. De outro lado, utilizar a experimentação para avaliar a "construção de conceitos" (três indicações) está em concordância com uma concepção construtivista, ou seja, a avaliação parte do pressuposto que os conhecimentos são construídos, numa posição em que professor e alunos são partes ativas do processo educacional. Todavia, nota-se uma incoerência nas respostas do participante P8 quanto aos momentos e objetivos para se utilizar da experimentação quando se analisa os fundamentos da aprendizagem, em que ao mesmo tempo que se busca "verificar a transmissão correta de conceitos" (abordagem mais comportamentalista), há também a finalidade de "avaliar a construção de conceitos" (numa abordagem mais construtivista) - assim, ambas as abordagens parecem coexistir em sua concepção sobre experimentação.

Ainda tendo como base os momentos em que a experimentação é utilizada em sala de aula, destaca-se a intenção de usá-la para complementar conceitos já estudados (seis citações). Isso pode significar que a experimentação é entendida como dissociada da teoria, ou ainda, como um incremento (e não parte constituinte) do processo de ensino-aprendizagem das Ciências Naturais (ao invés de entendê-las como dotadas de natureza teórico-prática). 
Os professores participantes ao serem questionados se haveria condições mínimas necessárias para se trabalhar com atividades experimentais no cotidiano das escolas, responderam de maneira bastante distinta (Tabela 5):

\begin{tabular}{l|l}
\hline $\begin{array}{c}\text { CONDIÇÕES MÍNIMAS NECESSÁRIAS PARA SE TRABALHAR } \\
\text { COM ATIVIDADES EXPERIMENTAIS }\end{array}$ & \multicolumn{1}{c}{ PROFESSORES } \\
\hline Não existe & $\mathrm{P} 2, \mathrm{P} 3, \mathrm{P} 4, \mathrm{P} 6$ \\
\hline Existe & $\mathrm{P} 1, \mathrm{P} 5, \mathrm{P} 7$ \\
\hline Não respondeu & $\mathrm{P} 8$ \\
\hline
\end{tabular}

Tabela 5 - Condições mínimas para se realizar atividades experimentais segundo os sujeitos. Fonte: Elaboração dos autores (2019).

Entre os que concordaram que se devem ter condições mínimas para a promoção da experimentação, as justificativas foram: a necessidade de haver materiais, espaços adequados e apoio da escola para a sua realização. Todavia, o professor P8, que não declarou resposta nesta pergunta, afirmou num outro questionamento que deveria haver, no mínimo, "predisposição do professor e motivação dos alunos" para a proposição de experimentos. Na mesma linha, um dos professores (P2) que indicou não haver condições específicas, afirmou, em seguida, a necessidade de se ter "materiais específicos".

Outro aspecto a ser considerado é que, além de atuarem nas suas respectivas áreas de formação, quatro dos participantes afirmaram lecionar ou já terem lecionado em outros componentes curriculares, desde as áreas afins - como a Química, a Física, a Biologia e Ciências, no Ensino Fundamental - até componentes de outras áreas (como Geografia, Artes e Matemática), o que sugere que a não promoção de atividades experimentais pode ter como um de seus fatores o não domínio conceitual sobre o que envolve a experimentação, especialmente por não fazerem parte de suas formações iniciais.

Quando perguntados sobre quais tipos de experimentação conheciam (e não necessariamente utilizavam), os profissionais responderam que tinham conhecimentos sobre as seguintes abordagens (Tabela 6):

\begin{tabular}{l|l}
\hline \multicolumn{1}{c|}{ TIPOS DE EXPERIMENTAÇÃO CONHECIDA } & \multicolumn{1}{c}{ PROFESSORES } \\
\hline Investigativa & $\mathrm{P} 1 \mathrm{P} 2, \mathrm{P} 3, \mathrm{P} 5, \mathrm{P} 7, \mathrm{P} 8$ \\
\hline Demonstrativa & $\mathrm{P} 1, \mathrm{P} 2, \mathrm{P} 3, \mathrm{P} 4, \mathrm{P} 5, \mathrm{P} 7, \mathrm{P} 8$ \\
\hline Verificação & $\mathrm{P} 1, \mathrm{P} 2, \mathrm{P} 3, \mathrm{P} 4, \mathrm{P} 5, \mathrm{P} 7$ \\
\hline Não declarou & $\mathrm{P} 6$ \\
\hline
\end{tabular}

Tabela 6 - Tipos de experimentação conhecidos pelos professores. Fonte: Elaboração dos autores (2019). 
Um dos sujeitos afirmou não conhecer nenhuma delas e outros seis afirmaram conhecer a experimentação investigativa, assim como sete deles indicaram saber sobre a experimentação demonstrativa e seis sobre a experimentação para verificação. Isso sugere que a não utilização da experimentação investigativa, por exemplo, ocorreria por outros fatores que não incluem o desconhecimento dessa abordagem (podendo ser, inclusive, por limitações estruturais ou por opção metodológica). Todavia, quando questionados sobre as categorias que afirmaram conhecer, apenas três dos professores (P1, P4 e P7) as descreverem, mesmo que parcial e superficialmente.

Por fim, ao serem questionados sobre a importância da experimentação, todos a consideram como relevante na prática pedagógica para a promoção da aprendizagem, de modo que justificaram que com a experimentação (Tabela 7):

\begin{tabular}{c|l}
\hline PROFESSORES & \multicolumn{1}{c}{ RESPOSTA } \\
\hline P1 & $\begin{array}{l}\text { "É possível motivar os alunos e tornar o conhecimento científico mais próximo } \\
\text { deles". }\end{array}$ \\
\hline P2 "É relevante para situar o aluno num contexto". \\
\hline P3 & $\begin{array}{l}\text { "Para que o estudante possa construir conceitos significativos e ter uma maior } \\
\text { autonomia no processo de ensino e aprendizagem". }\end{array}$ \\
\hline P4 & "Tornar a aprendizagem mais significativa". \\
\hline P5 & $\begin{array}{l}\text { "Despertar o interesse em aprender e colaborar na construção significativa do } \\
\text { aprendizado". }\end{array}$ \\
\hline P6 & $\begin{array}{l}\text { "Pois as atividades experimentais se caracterizam como algo mais fácil de atingirmos } \\
\text { a aprendizagem do aluno". }\end{array}$ \\
\hline P7 & $\begin{array}{l}\text { "Porque a Química é uma ciência que trabalha com o abstrato e a experimentação é } \\
\text { uma forma de articular o macro com o micro". }\end{array}$ \\
\hline "Nesse aspecto o aluno demonstra autonomia, e constrói o seu próprio \\
conhecimento".
\end{tabular}

Tabela 7 - Importância das atividades experimentais de acordo com os entrevistados. Fonte: Elaboração dos autores (2019).

Em síntese, todos acreditam que a experimentação pode facilitar o ensino-aprendizagem das Ciências Naturais, considerando para isso a adoção de uma abordagem construtivista da aprendizagem - apesar de tais aspectos não estarem coerentes e fundamentalmente presentes nos relatos de suas ações docentes.

\subsection{Análise das entrevistas semiestruturadas}

Considerando as respostas dadas pelos três professores (P1, P4 e P8, uma de cada componente curricular das Ciências Naturais aqui abordadas) que participaram da entrevista semiestruturada, identificou-se que todas elas afirmaram utilizar atividades experimentais em 
sala de aula - mesmo antes do ingresso na pós-graduação em nível de mestrado, uma vez que as consideram de fundamental importância para os processos de ensino-aprendizagem.

$\mathrm{O}$ entrevistado $\mathrm{P} 4$, por exemplo, afirmou que considera a experimentação relevante "porque o aluno vai aprender na prática, consolidando o conhecimento" - fato este que é fundamentado por Moreira e Atx (1991, p. 88), ao argumentarem que se deve utilizar experimentos como um ponto de partida para desenvolver a compreensão conceitual, encaixando-as em momentos propícios para que os alunos percebam sua relação com as ideias discutidas em sala de aula.

O sujeito P1, por sua vez, argumentou que as atividades experimentais "fazem a Ciência ser mais próxima do aluno, desmistifica a visão que a Ciência é só feita em laboratório e por cientistas" - sendo que tal concepção está relacionada à ideia de não se promover visões deformadas da Ciência e do trabalho científico, conforme descrevem Gil-Pérez et al. (2001) e Cachapuz (2005).

Já em relação ao professor P8, ele considera que a experimentação pode ser usada como forma de avaliação, uma vez que com ela "tem-se um melhor retorno dos alunos acerca do processo de ensino-aprendizagem".

Ao serem questionadas sobre a última prática experimental que haviam realizado, os professores relataram, de maneira geral, que durante as atividades o interesse dos alunos pela aula teve um aumento significativo. Além disso, complementaram afirmando que as suas funções, enquanto professores, foram de orientadores, uma vez que os próprios alunos deveriam seguir um roteiro pré-estabelecido, cujas atividades eram geralmente de caráter ilustrativo. De acordo com a P8, “as atividades práticas são mais trabalhosas, mas o envolvimento do aluno é maior. [Eles] se empenham em todas as fases do processo". Neste mesmo sentido, Moreira e Atx argumentam que:

[...] a maneira com que a experimentação é utilizada joga um papel mais importante do que a própria experimentação em si. A aceitação dos alunos está muito mais ligada a esse fato. (É necessário) um curso que faça amplo emprego de experimentação, que se fundamenta nela, que permita que ela comande o andamento do ensino, que leve o aluno a refletir e ao professor descobrir as dúvidas com que seus alunos se defrontam (MOREIRA; ATX, 1991, p. 88).

Neste contexto, os três professores foram unânimes quanto aos recursos mínimos para promover a experimentação, alegando que é fundamental o interesse e a dedicação por parte dos professores. Tal afirmação é exemplificada pela fala de P4: "se o professor quiser realizar atividades experimentais, ele realiza de qualquer forma”. Todavia, esta concepção confere aos 
professores toda a responsabilidade para o desenvolvimento da experimentação em sala de aula, minimizando outros fatores que compõem a prática e o contexto educacional.

Em contrapartida, pode-se citar Moreira e Atx (1991) quando afirmam que a correspondência do material às condições de ensino-aprendizagem afeta diretamente a realidade escolar, uma vez que nem todas as escolas possuem laboratórios, o que acaba ficando a cargo do professor propor materiais alternativos que possam ser utilizados em sala de aula. Inclusive, discute-se que esse fato é ainda mais preocupante nas cidades do interior e na zona rural, onde a disponibilidade de alguns materiais, muitas vezes, é insuficiente ou até mesmo inexistente, cabendo ao professor criar alternativas e adaptações que superem esses obstáculos - fato constatado também por Valentim (2017) ao destacar que tal realidade não se diferencia de muitas escolas brasileiras.

$\mathrm{Na}$ mesma perspectiva, as entrevistadas relataram que apesar dos desafios enfrentados, existe a viabilidade de todos os conteúdos, comumente trabalhados no Ensino Médio, serem ensinados numa abordagem experimental, considerando a viabilidade da utilização de materiais alternativos.

Ademais, os entrevistados relataram também que a carga horária dos componentes Física, Química e Biologia, nas matrizes curriculares das escolas, acabam inviabilizando o desenvolvimento de um maior número de atividades de cunho experimental. Já no que se refere às teorias de aprendizagem que orientam as práticas docentes, inclusive nas abordagens com experimentos, surgiram respostas bastantes distintas: P1 afirmou que suas práticas tendem mais a uma concepção comportamentalista, baseada na reprodução, inclusive citando a teoria de reforço de Skinner (o que contradiz epistemologicamente a indicação feita anteriormente, no questionário, ao qual afirmou que dentre os motivos para utilizar a experimentação seria para "compreender como se dá o conhecimento científico" e "promover a construção conceitual", conforme o Tabela 3); P4 relatou que segue uma linha mais construtivista, porém não utiliza abordagens experimentais do tipo investigativo; e P8 apontou que também segue uma linha mais construtivista, especificamente a da aprendizagem significativa de Ausubel, Novak e Gowin, utilizando também mapas conceituais e abordagens investigativas.

\section{CONSIDERAÇÕES E LIMITAÇÕES}

Deste modo, pode-se constatar que a realidade enfrentada em sala de aula não diverge significativamente dos desafios destacados por diversas publicações científicas desde o final do século passado, principalmente no que se refere às potencialidades e limitações de se realizar 
atividades experimentais em sala de aula. Além disso, foi possível identificar que as três categorias de experimentação (investigativa, demonstrativa e de verificação) estiveram presentes - em maior ou menor grau - nos relatos das práticas pedagógicas dos professores participantes da pesquisa, bem como das diferentes abordagens teóricas de aprendizagem (tanto a mais comportamentalista, quanto a mais construtivista).

Ademais, de acordo com as respostas dadas pelos sujeitos, pode-se perceber a importância do uso da experimentação no processo de ensino-aprendizagem, especialmente quando ela é teórico e metodologicamente fundamentada, além de que há vontade por parte dos professores em realizá-la - mesmo que para isso tenham de providenciar materiais alternativos para a sua execução.

Cabe destacar também que, com base nas entrevistas, percebe-se uma possível ressignificação, sobretudo após ingresso no programa de pós-graduação em nível de mestrado profissional, de muitas das concepções sobre as atividades experimentais e das teorias de aprendizagem que as fundamentam, principalmente sobre a ideia do papel do professor e dos alunos no processo de construção de conhecimentos científicos.

Neste sentido, estudos como este podem sugerir a necessidade de ressignificação da formação inicial, sobretudo em relação ao desenvolvimento de uma base epistemológica adequada sobre a experimentação para o ensino de Ciências Naturais, ao mesmo tempo que aponta a necessidade de políticas públicas mais elaborados que oportunizem a formação continuada através da participação em programas de pós-graduação que possibilitem ao professor as condições teóricas e práticas necessárias para que uma nova e melhor ação docente seja constituída.

Por último, é importante esclarecer que analisamos as narrativas dos sujeitos mediante a aplicação de questionários e entrevistas semiestruturadas, mas não observamos as suas práticas pedagógicas in loco. Portanto, divergênicas entre discurso e prática podem ocorrer, concretizando uma limitação deste estudo, ao mesmo tempo, que amplia espaços para pesquisas futuras que abordem essa vertente.

\section{AGRADECIMENTOS}

Agradecimentos ao Programa de Pós-Graduação em Ensino de Ciências Naturais (PPGECN) e ao Laboratório de Pesquisa e Ensino de Química (LabPEQ) da Universidade Federal de Mato Grosso (UFMT). 


\section{REFERÊNCIAS}

ARAÚJO, M. S. T.; ABIB, M. L. V. S. Atividades Experimentais no Ensino de Física: diferentes enfoques, diferentes finalidades. Revista Brasileira de Ensino de Física, v. 25, n. 2, junho, 2003, p. 176-194. Disponível em: <http://www.scielo.br/pdf/rbef/v25n2/a07v25n2.pdf>. Acesso em: 12 out. 2018.

BASSOLI, F. Atividades práticas e o ensino-aprendizagem de ciência(s): mitos, tendências e distorções. 2014. Ciência e Educação, v. 20, n. 3, 2014, p. 579-593. Disponível em: <www.scielo.br/pdf/ciedu/v20n3/1516-7313-ciedu-20-03-0579.pdf >. Acesso em: 08 jan. 2020.

BOGDAN, R. C.; BIKLEN, S. K. Investigação qualitativa em Educação: uma introdução à teoria e aos métodos. Porto (Portugal): Porto Editora, 1994.

CACHAPUZ, A. Superação das visões deformadas da Ciência e da Tecnologia: um requisito essencial para a renovação da educação científica. In: CACHAPUZ, A; GIL-PÉREZ, D.; CARVALHO, A. M. P.; PRAIA, J.; VILCHES, A. (Orgs.). A necessária renovação do ensino de Ciências. São Paulo-SP: Editora Cortez, 2005.

CERQUEIRA, T. C. S., et al. O autoconceito e a motivação na construção da subjetividade: conceitos e relações. Intermeios: Revista do Mestrado em Educação, Campo Grande - MS, v.10, n 20, p. 30-41, 2004. Disponível em:

〈www.seer.ufms.br/index.php/intm/article/download/2584/1833〉. Acesso em: 10 out. 2018.

GIL-PÉREZ, D., et al. Para uma imagem não deformada do trabalho científico. Revista

Ciência \& Educação, v. 7, n. 2, 2001, p. 125-153. Disponível em:

<http://www.scielo.br/pdf/ciedu/v7n2/01.pdf>. Acesso em: 10 out. 2018.

GIORDAN, M. O papel da experimentação no Ensino de Ciências. Revista Química Nova na Escola, n. 10, p. 43-49, 1999. Disponível em:

<http://qnesc.sbq.org.br/online/qnesc10/pesquisa.pdf>. Acesso em: 11 out. 2018.

GONSAlVES, E. P. Iniciação à Pesquisa Científica. 4ª ed. Campinas - SP: Alínea, 2007.

HODSON, D. Experimentos na Ciência e no Ensino de Ciências. Tradução de Paulo A. Porto. Originalmente publicado em: Educational Philosophy and Theory, 20, 1988, p. 53-66.

Disponível em: <www.iq.usp.br/palporto/TextoHodsonExperimentacao.pdf>. Acesso em: 08 jan. 2020.

LOPES, A. R. C. Livros didáticos: obstáculos ao aprendizado da Ciência Química. Revista Química Nova, v. 15, n. 3, 1992, p. 254-261. Disponível em:

<http://quimicanova.sbq.org.br/imagebank/pdf/Vol15No3_254_v15_n3_\%2816\%29.pdf >.

Acesso em: 05 out. 2018.

LOPES, A. R. C. Obstáculos epistemológicos nos livros didáticos de Química. In: LOPES, A. R. C. Currículo e epistemologia. Ijuí-RS: Ed. Unijuí: 2007. 
LEITE, F. T. Metodologia Científica: métodos e técnicas de pesquisa (monografias, dissertações, teses e livros). Aparecida - SP: Ideias e Letras, 2008.

MOREIRA, M. A.; ATX, Rolando. Tópicos em Ensino de Ciências. Porto Alegre - RS: Sagra, 1991.

MOREIRA, M. A. Teorias de Aprendizagem. São Paulo - SP: EPU, 2011.

OLIVEIRA, J. R. S. Contribuições e abordagens das atividades experimentais no Ensino de Ciências: reunindo elementos para a prática docente. Acta Scientiae, v. 12, n. 1, jan./jun., 2010. Disponível em: <http://w3.ufsm.br/laequi/wp-content/uploads/2015/03/contribuições-eabordagens-de-atividades-experimentais.pdf > . Acesso em: 05 out. 2018.

OLIVEIRA, N.; SOARES, M. H. F. B. As atividades de experimentação investigativa em Ciência na sala de aula de escolas de ensino médio e suas interações com o lúdico. In Anais do XV Encontro Nacional de Ensino de Química, Brasília, 2010. Disponível em: <www.sbq.org.br/eneq/xv/resumos/R1316-1.pdf>. Acesso em: 08 out. 2018.

SILVA, R. R.; MACHADO, P. F. L.; TUNES, E. Experimentar sem medo de errar. In: SANTOS, W. L. P.; MALDANER, O. A. (Orgs.). Ensino de Química em Foco. Ijuí-RS: Ed. Unijuí, 2011. p. 231-261.

SOARES, M. H. F. B. O Lúdico em Química: Jogos e Atividade Aplicados aos Ensino de Química. 2004. 203 f. Tese (Doutorado em Química) - Programa de Pós-Graduação em Química, Universidade Federal de São Carlos, São Carlos-SP, 2004.

VALENTIM, J. A. Extração de óleos essenciais por arraste a vapor. 2017. 108 f. Dissertação (Mestrado em Ensino de Ciências Naturais) - Programa de Pós-Graduação em Ensino de Ciências Naturais, Universidade Federal de Mato Grosso, Cuiabá-MT, 2017.

Submetido em: 16 de outubro de 2019. Aprovado em: 14 de dezembro de 2019. 